\title{
WestVirginiaUniversity
}

THE RESEARCH REPOSITORY @ WVU

Graduate Theses, Dissertations, and Problem Reports

2003

\section{Relationship marketing elements in radio station websites}

Mark L. Atkinson

West Virginia University

Follow this and additional works at: https://researchrepository.wvu.edu/etd

\section{Recommended Citation}

Atkinson, Mark L., "Relationship marketing elements in radio station websites" (2003). Graduate Theses, Dissertations, and Problem Reports. 1366.

https://researchrepository.wvu.edu/etd/1366

This Thesis is protected by copyright and/or related rights. It has been brought to you by the The Research Repository @ WVU with permission from the rights-holder(s). You are free to use this Thesis in any way that is permitted by the copyright and related rights legislation that applies to your use. For other uses you must obtain permission from the rights-holder(s) directly, unless additional rights are indicated by a Creative Commons license in the record and/ or on the work itself. This Thesis has been accepted for inclusion in WVU Graduate Theses, Dissertations, and Problem Reports collection by an authorized administrator of The Research Repository @ WVU. For more information, please contact researchrepository@mail.wvu.edu. 


\title{
Relationship Marketing Elements in Radio Station Websites
}

\author{
Mark L. Atkinson \\ Thesis submitted to the Perley Isaac Reed \\ School of Journalism \\ at West Virginia University \\ in partial fulfillment of the requirements \\ for the degree of \\ Master of Science \\ in Journalism \\ Archie Sader, M.B.A., Chair \\ Denny Godfrey \\ Terry Wimmer, Ph.D. \\ Pamela Yagle, M.S.J. \\ Perley Isaac Reed School of Journalism
}

Morgantown, WV 2003

Keywords: Relationship Marketing, Radio Stations, Websites,

Webpages 


\section{ABSTRACT \\ Relationship Marketing Elements in Radio Station Websites}

\section{Mark Atkinson}

The purpose of this study is to determine whether or not radio station website designers effectively use relationship marketing to achieve the goals of the stations and their websites. The study is a comparison/content analysis of the websites of 150 radio stations, in three different formats, in the top 50 U.S. population centers. This study compared the results of a content analysis with the results of a 2000 Edison/Arbitron survey which asked respondents to rank 14 website features according to what those replying considered important. This study sought to determine whether the more popular features actually appeared on more websites than did the less popular Internet features. Unexpectedly, that was not the case. A website feature's popularity did not seem to be linked to its frequency of occurrence; some popular features appeared on only a few websites, and some relatively unpopular features were more prevalent. In conclusion, website designers do not necessarily take visitor preference into account when designing a radio station's webpage; they, therefore, forgo an effective method of fostering relationships. 


\section{Contents}

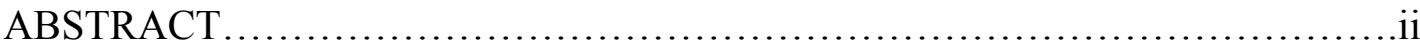

\section{Sections}

1. Introduction.

\section{LITERATURE REVIEW}

2. Importance of Relationship Marketing....................................4

3. Definitions, Benefits, and Ingredients of Relationship Marketing..............6

4. Relationship Marketing and Website Construction..........................19

\section{METHODOLOGY}

5. List of Website Features To Be Surveyed................................ 30

\section{RESULTS}

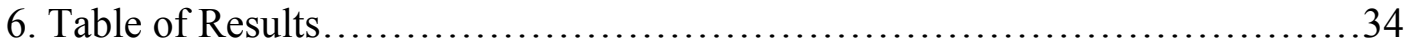

7. Comparison Between Popularity and Actual Occurrence of Features............35

8. Website Construction Across Three Formats................................... 37

DISCUSSION AND FUTURE RESEARCH

9. Conclusions......................................................... 57

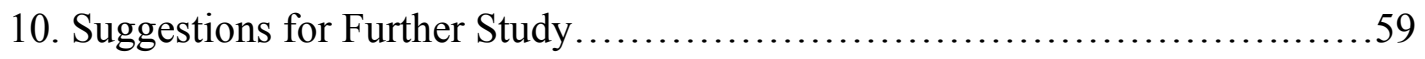

\section{APPENDIXES}

11. Markets and Stations Analyzed..........................................61

12. Content Analysis Results...........................................68

13. Works Cited....................................................... 70 


\section{Introduction}

Relationship marketing is becoming increasingly more popular in all types of businesses and organizations. In their search for a competitive edge, companies of all sorts are devoting time and resources toward establishing strong bonds with their suppliers, customers and target markets. Radio stations and their websites are no exception.

Radio stations, whether commercial or public, have a unique opportunity to achieve their goals by using relationship marketing and their webpages. Every radio station has an ultimate objective. In the case of a commercial station, that goal may be to make a profit via selling advertising; in the case of public radio, it may be to entertain and to educate (while maintaining the station's operations). In any case, an important facet of meeting that objective is to increase or to maintain high listenership levels. Public radio groups will need listeners and sponsors that are also willing to pay for what they hear. Any station's webpage can be an effective tool for achieving that goal. While quality programming is the core service that any radio station works to offer its listeners, a website can augment the benefits a listener receives. 
The quality of a station's webpage does not directly affect the quality of the station's programming. Although the webpage cannot help the radio station meet its goal of a large audience, a webpage can assist a radio station in building relationships with site visitors. It can do that by encouraging repeat traffic, causing visitors to return, which is the website's basic objective.

The focus of this study will be relationship marketing as it relates to achieving the goal of the webpage. The study will determine how commercial radio stations foster relationships using their websites. Ideally, it will tell if the station websites are luring site visitors to make repeat visits by offering the features that visitors claim to want to see. If they are not, then they are missing opportunities for building relationships through repeat visits.

Before that can happen, the study will deal with some related topics. The first thing that this study will acknowledge is the increasing importance of relationship marketing in business relationships; it will point out that the trend towards relationship marketing is an unavoidable part of a successful business. Next, the study will cull a specific definition of relationship marketing from the number of existing descriptions. The literature review will then show how the definition and general points of relationship 
marketing can apply specifically to radio station website use. It will also point out the benefits, both to the firm and to customers, of establishing a strong relationship. That will illustrate the reasons for wanting to devote resources to relationship marketing. The next part of the review will identify and define the important ingredients of a relationship, along with their antecedents and outcomes. That will determine what state of mind needs to exist between the two parties in order to truly establish a relationship. Finally, the review will examine both general marketing tactics and website design strategies that will effectively foster relationships between the radio station and its site visitors. At that point, the study will examine how existing radio station websites actually go about building relationships with site visitors. Then it will make comparisons and determine whether or not these tactics are similar to the ones that will most likely be effective. 


\section{Literature Review}

\section{Growing Importance of Relationship Marketing}

Relationship marketing has, for some time, been receiving recognition as an important strategy in any business environment. Morgan and Hunt acknowledge the gradual but fundamental shift in the field of marketing toward relationship building and cooperation. Flat-out competition between businesses is fading; the trend now is toward collaboration, both with other companies and with customers (1994). Ganesan, too, recognizes that "with increasing frequency, manufacturers and suppliers are reporting a change in the nature of buyer-seller relationships" (1994). Companies can achieve a sustainable competitive advantage by fostering loyalty in customers, partners and suppliers (Ganesan 1994).

Shifting the focus of marketing from gaining new customers to retaining existing customers is the foundation of this "sustainable competitive advantage" (Berry 1995). The attraction of new customers is, more and more, being accepted as simply an intermediate stage in the marketing process, rather than its final end. In both marketing practice and research, the competitive value of obtaining the loyalty of a customer or partner is 
becoming more and more apparent, particularly in the case of serviceproviding companies (Berry 1995).

Though relationship marketing is an issue of growing importance in all types of businesses, it is particularly germane for service providers. When a business provides a service (radio station websites could be service providers), relationships and customer loyalty are especially important because of the intangible nature of the "product" (Crosby and Evans 1990). Since there is nothing concrete for the customer to evaluate when receiving a service, loyalty and relationship strength become particularly important in maintaining continued business for a service provider. Also, an increasing number of firms are realizing that, when dealing with an intangible service, a relationship that is satisfactory overall will prompt customers to overlook some unsatisfactory encounters they may have had (Berry 1995). In all, the school of marketing thought has acknowledged that relationship marketing is an important aspect of successful business transactions. That importance also applies to online relationships. 


\section{Definitions of Relationship Marketing}

But what is relationship marketing exactly? Marketing researchers have advanced a variety of definitions for the term "relationship marketing" and few are exactly the same. This study needs a working definition.

Morgan and Hunt adopt a fairly broad definition of relationship marketing in their commitment-trust study. They maintain that relationship marketing "refers to all marketing activities directed toward establishing, developing, and maintaining successful relational exchanges" (1994, p. 22). One key idea to take from this definition is that of the relational exchange, as opposed to a single, specific transaction. Focusing solely on a discrete exchange of product or performance for money is at the opposite end of the strategic spectrum from relationship marketing. Relational customer orientation is typified by cooperative action and planning for the future (Garbarino and Johnson 1999). Expectations of future interactions and an attitude of cooperation are two common traits of relationship marketing that, along with others to be examined, will go into this study's definition of relationship marketing.

Gronroos' statement of the goal of relationship marketing echoes that attitude of relationship marketing: “...to establish, maintain, and enhance 
relationships... at a profit, so that the objectives of the parties involved are met" (1990, p. 138). Enhancement of the relationship is particularly important. As Berry has stated, attracting customers (or partners) is an intermediate step in relational marketing; fostering loyalty is the ultimate aim and improving a relationship is one important way to achieve that aim. Cooperation between the two parties will ensure that they meet the needs of both. If the relationship is beneficial to the customer then it would behoove them to stay in the relationship.

There are several points to take from these four definitions. The idea of maintaining relational exchanges (as opposed to limiting attention to single transactions) is common among all definitions, as is the idea that attracting customers is only a step on the way to retaining them. Finally, the definitions of relationship marketing generally include the need for cooperation between relationship partners. Cooperation consists of certain actions and mindsets which will be covered shortly. At any rate, for the purposes of this study, those three main points will be central to its definition of relationship marketing: all cooperative activities geared towards attracting AND maintaining customers, and instilling in them the mindset of ongoing interactions 


\section{Relationship Marketing and How \\ it Applies to Radio Station Websites}

Radio station websites might not, at first, seem to be able to apply relationship marketing to their transactions. One of the most basic business relationships involves a customer purchasing a product from a retailer. Relational marketing is then used to encourage the customer to continue to purchase the product from that retailer. At first glance, the website/site visitor relationship does not appear to have any components in common with the retailer/customer relationship. Money does not change hands and site visitors do not receive a physical product.

On further examination, however, there are a number of ways in which relationship marketing can apply to website construction. Morgan and Hunt acknowledge that a "customer", as such, does not need to be a member of a relationship. From their catalog of ten distinct forms of relational marketing, one form seems to best describe the relationship between a website and a site visitor: "relational exchanges involving service providers, ... and their clients" (1994). They point out that a service can take the place of an actual 
product. The service, in this case, is the website itself and the benefits it offers to the visitor (or "client"). And while the "clients" do not pay money for the service, they do make an investment of time and effort when visiting the site. Relationship marketing's role in this scenario is to keep the visitors returning to the site.

Also, website designers can incorporate three of the five elements of relationship building into a website's construction. Those elements are a core service to offer consumers (visitors), customization of the relationship to the individual customer, and added benefits to the core service (Berry 1995). Again, none of these elements involve an exchange of money or a tangible product.

The way for the site owner, or any service provider, to achieve a service relationship is via a mutual exchange and fulfillment of promises (Bitner 1995). The key is for the service provider (or website owner) to clearly state and fulfill its role. If the service provider does this, the client's (or site visitor's) desired response will be a preference for and loyalty to that provider (Pisharodi and Langley 1990). As long as the situation meets these basic criteria, the idea of relationship marketing can apply to service situations in which money does not change hands. 


\section{Benefits of Relationship Marketing}

This section will examine the benefits, for both service providers and clients, of a successful relationship. This will explain the reasons website owners have for attempting to establish and maintain relationships with their site visitors.

Studies have shown that each website user regularly visits less than twelve different sites (Gapper 1998). That makes it particularly important for a site to establish itself as one of those twelve in the opinion of its desired visitors. Site owners need an advantage over other sites in order to entice internet users to visit repeatedly. Relational marketing is one way for service suppliers to establish those "greater sustained competitive advantages" (Dupont 1998, p.11). But what, specifically, are these advantages?

The foremost advantage for a firm or supplier is the "customer insurance" that a relationship affords them. A customer's overall satisfaction with a service provider is an attitude-like construct. Satisfaction is an accumulation of separate evaluations (Garbarino and Johnson 1999). In the case of repeat customers, all previous transactions, along with the current one, influence satisfaction (Pisharodi and Langley 1990). In other words, one bad 
experience will not mar an extensive, generally satisfactory relationship with a provider. Because of this, customers in a relationship will be less likely to switch to another supplier (Sharma 1999).

Another important relationship advantage for suppliers involves cost. It is generally more cost-effective to maintain a relationship with current customers than to attract new ones (Berry, Levitt and Lovelock 1983). Reicheld and Sasser's analysis supports that idea. They found that when customer defections are reduced by 5 percent, profits can climb between 25 and 85 percent (1990). Relationships mainly raise profits by lowering marketing costs, since a firm does not have to invest as much into attracting new customers if they have numerous existing customer accounts (Sharma 1999). In addition to lowering marketing costs, relationships allow firms to use positive word-of-mouth from existing customers to supplement their marketing (Greenbaum 2000). As mentioned earlier, websites generally do not garner a direct monetary profit from their visitors. However, each site has a goal that depends on steady site traffic. That, coupled with the investments in time, money and effort that go into a website, indicates that the advantages of relationship marketing hold true in the case of radio station websites. 
The benefits of relationships are not one-sided, however. If that were the case, there would be little incentive for a customer to enter into one. That is useful for the service provider, as well, because the more benefits they can offer the customer, the more likely it is that the customer will stay with them.

Convenience is one main benefit that relationships offer. Customers tend towards relationships when they need some sort of continuously delivered service (that could include websites). This is partly because they do not have to constantly evaluate the service's quality (Berry 1995). Service relationships simplify the customers life and reduce stress because they preclude the need for change (Bitner 1995).

Value is the other main benefit that a relationship holds for a customer. If a customer does not have to change service providers, then they also do not have to deal with the transaction costs of switching (Schlenker, Helm and Tedeschi 1973). Not only does a relationship save them the cost of switching, but often will provide advantages not available in a short-term or transaction-by-transaction relationship (Marshall, Palmer and Weisbart 1979). Continuous interaction allows providers to customize services for each customer. These are all general reasons why, in many cases, it is desirable for customers and service providers both to be in relationships. 
Ingredients of a Relationship

Now this study will explore the ingredients of a relationship. The purpose of this section is to identify the behaviors and attitudes that are most critical to forming and maintaining strong relationships.

Part of the definition of relationship marketing advanced earlier in this study deals with expectations of future interactions and ongoing transactions. Attitudes and mindsets that determine long-term orientation have been the topic of several marketing studies. Researchers have agreed that two of the most important determinants of long-term orientation are trust and commitment.

While definitions of trust and commitment vary somewhat from study to study, they both recur as determinants of a partner's orientation. In other words, trust and commitment need to be present in a partner's mindset for them to plan to remain in a relationship. 


\section{Trust and Its Antecedents}

Morgan and Hunt define trust as confidence in a partner's reliability and integrity (1994). A partner can also direct the attitude of trust towards the product or services offered (Garbarino and Johnson 1999). Another definition of trust is "a willingness to rely on an exchange partner in whom one has confidence" (Moorman, Zaltman, and Deshpande 1992, 2). Ganesan's 1994 study found that trust is a significant ingredient in determining long-term orientation. High levels of trust in a relationship will also decrease uncertainty and increase the likelihood of conflicts being solved in an amicable fashion (Morgan and Hunt 1994). Trust in a partnership, along with commitment, is also significant in distinguishing relational customers, or those with a long-term mindset, from transactional customers (Garbarino and Johnson 1999).

There are also component attitudes and behaviors that foster and make up trust, just as trust is a component of a long-term relationship and long-term orientation. Credibility is one component that is significant in developing trust and, therefore, long-term orientation. Credibility is the extent to which 
the customer believes that the service provider has the expertise to perform the job effectively (Ganesan 1994).

Open, two-way communication is another antecedent of trust between a client and a service provider (Berry 1995). It aligns perceptions and helps customers know what to expect from their suppliers (Morgan and Hunt 1994). Open communication also gives a client the perception of having special status (Czepiel 1990). In fact, in one study, 80 percent of the subjects surveyed felt that it was important for a company to stay in touch with its customers (Cottrell 1994).

There are other antecedents of trust, as well. Ganesan found that experience with a partner breeds trust, as does satisfaction with the outcomes of the relationship. Both of these antecedents tie into the idea of relationalism, which is the perception that a favorable outcome for one partner will benefit the other. This perception of relationalism is also an important ingredient of trust (1994). Finally, honest, consistent behavior can instill a feeling of trust in relationship partners (Sharma 1999). 


\section{Commitment and Its Antecedents}

Morgan and Hunt describe commitment as the belief that a relationship with a particular partner is valuable enough to warrant a maximum effort at maintaining it (1994). Garbarino and Johnson's definition of commitment ties into the idea of relationalism mentioned earlier: loyalty for, psychological attachment to, and concern for the future welfare of a relationship partner (1999). Commitment deals with a partner's future intentions concerning the relationship; whether they will work to maintain the relationship or will search for another partner. High levels of commitment reduce the likelihood that a partner will end the relationship (called the propensity to leave) (Morgan and Hunt 1994).

As with trust, there are several antecedents for commitment. The expectation of high termination costs for ending a relationship will generate commitment. If it is expensive to leave a relationship, or if partners think it will be expensive, then there will be more motivation from both partners to maintain it. Also, the more benefits a customer receives, the more valuable they will perceive the relationship to be, and they will be more committed to maintaining it (Morgan and Hunt 1994). 
Generally speaking, commitment and trust are both significant in determining a relationship partner's future intentions. It would behoove any vendor or service supplier, including website owners, wishing to strengthen a relationship with their clients to attempt to foster strong senses of trust and commitment.

\section{Other Ingredients of Relationships}

While high levels of trust and commitment are the most widely acknowledged components of a highly relational mindset, there are other important ingredients and determinants of strong relationships.

The most important of these "miscellaneous" components of relationship building is "the mutual exchange and fulfillment of promises" (Bitner 1995, 246). The use of promises is particularly important in service relationships such as those between websites and site visitors (Gronroos 1990). Promises and guarantees help to build trust and pacify unsatisfied customers (Berry 1995). However, keeping promises, as opposed to simply making them, is the key to maintaining relationships (Calonius 1988).

The idea of promise fulfillment enhancing relationships is related to the idea of the alignment of expectations mentioned by Morgan and Hunt 
(1994). The first step of fulfilling promises is making realistic promises. If the service provider does that, it makes certain that the client and service provider expect the same results and that the provider can actually fulfill those expectations. The service provider next needs to enable delivery of the service. He does this by making sure sufficient qualified employees and service systems are in place to allow prompt and satisfactory delivery of the service. Actual promise keeping, the third step, occurs during each of the service encounters (or during each website visit in the case of this study). If the outcome matches or exceeds the expectation the client has, then the promise keeping has been successful (Bitner 1995). As with commitment and trust, promise keeping is an important component behavior of relationship building.

Two other relationship-enhancing behaviors mentioned in previous research are similar to one another: customer orientation and proactive behavior. Customer orientation is an understanding of the client's needs and an adaptation of services to match those needs. Proactive behavior involves anticipation of customer problems and development of solutions for those problems (Sharma et al., 1999). Both of these behaviors are related to the idea of adding benefits to a relationship to increase commitment. Clients are more likely to remain in a relationship if the service provider meets most of 
their needs and solves most of their problems without much inconvenience to them.

This section has identified the most important components, attitudes, and behaviors for enhancing a service provider/client relationship. Trust, commitment, and promise fulfillment are the most important ingredients for determining long-term orientation of relationship partners. Now the study will examine tactics for actually fostering these attitudes in a website/web visitor relationship.

Implementing Relationship Marketing in Website Construction

This section will enumerate actual tactics to strengthen relationships. It will identify the specific means by which service providers can foster trust, commitment, and a long-term mindset in a service relationship. The first part of this section will examine general marketing techniques for strengthening relationships. The second part will look at specific techniques for fostering loyalty in website visitors. Following that will be an examination of which techniques radio station websites are using to strengthen relationships with their site visitors and listeners. 


\section{General Relationship Marketing Tactics}

Dupont has proposed three levels on which any marketing relationship should operate. The levels are progressively harder to achieve, but also progressively harder for competitors to duplicate. The first and most basic level involves price incentives. The simplest way to make a relationship stronger is to lower the cost of the service below the cost of competing services (1998). Price incentives encourage loyalty by increasing a partner's commitment (a lower price makes the service more valuable; greater value diminishes the propensity of a partner to leave) (Berry 1995). Price incentives are the weakest and most easily imitated tactic, but all subsequent levels are based on them (Dupont 1998). Websites are nearly always free to use, of course, so price incentives are almost universal for radio station webpages.

The second level of a marketing relationship involves social bonds. Marketers create social bonds by personalizing the relationship during each service encounter. Regular communication with the client is the simplest way to personalize a relationship and to build trust (Dupont 1998). The service provider needs to do everything possible to make the client aware of his cooperative, as opposed to opportunistic, intentions. That, along with 
frequent contact with the customer, aligns expectations and demonstrates trustworthiness to the client (Crosby and Evans 1990). Building social bonds fosters both trust, through frequent communication, and commitment, through improved quality of service.

The third level of a marketing relationship deals with structural solutions to customers' problems. Structural solutions involve the addition of valueboosting benefits that are difficult for clients to find elsewhere. If done correctly, structural solutions are the hardest marketing level for competitors to imitate (Dupont 1998). In order to add this extra value, service providers need to become proficient at soliciting needs-related information from their clients (Crosby and Evans 1990). Once they find out what specific problems their customers face, marketers can offer a more customized product to each customer. They can add hard-to-duplicate benefits to the core service they offer, making their service more valuable (Berry 1995). By adding value, they increase the commitment of their clients, thereby fostering long-term orientation. 


\section{Website Construction Tactics}

While customer loyalty is important in all instances of relationship marketing, it is particularly valuable in the online environment. In the case of websites, loyalty is a more accurate measure of traffic than is number of hits (Thomases 2000). As pointed out earlier, the typical web user visits twelve websites regularly, making it important for a webpage to be established as one of those twelve (Gapper 1998). Loyalty to a website can be strengthened by giving the visitor good reasons to return (Thomases 2000). Customers will return to websites where they receive value for loyalty (Perez 2000).

An Edison Media Research and Arbitron survey identified features that radio station website visitors said they were most interested in seeing. These are the features that those "customers" consider the most valuable: the ability to listen to the radio station, information about local concerts, titles and artists of songs recently played on the station, the ability to enter contests, listings of places to visit in the local community, the opportunity to vote on whether songs are good or not, weather information, programming schedules, info on and pictures of disc jockeys, e-mail contact with the station, information on upcoming station appearances in the community, 
"Internet-only" audio, the ability to print out coupons from advertisers, and links for ordering station merchandise (2000). This study will focus on those features since survey subjects said that they had the most interest in them. Based on these findings, a website that uses the most of these features should be able to instill the most loyalty in its visitors, since these elements would offer the most value.

Core services are the base on which relationship marketing is built. Websites should have strong content to offer to their visitors (Thomases 2000). Using regularly updated, timely information is the most successful way to secure repeat visits to a webpage (Gapper 1998). It is also important for the designers of the website to make its purpose clear so that customers understand exactly what it offers (Business and Management Practices 1998). In the case of radio station websites, the core service, or point of interest, is the music of the station. As far as website features go, that would include the ability to listen to the station over the Internet, lists of songs being played, auxiliary audio, and a programming schedule.

With a core service in place, websites should next augment that service with added benefits. That will help visitors see using the Internet as a benefit rather than as a deficit. Priority service in exchange for loyalty will keep customers returning to the website (Perez 2000). Specialty 
information, particularly that which is hard to find anywhere else online, is a valuable addition to the core service. For example, in the case of radio website features, the abilities to print coupons, order station merchandise and check concert listings and local weather would all benefit visitors. Also, on-line competitions that require visitors to return to the site to view results will encourage repeat visits (Gapper 1998). Service customization for each individual user is another benefit likely to increase loyalty (Thomases 2000). As mentioned earlier, customers will consider on-line service valuable and harder to replace if it is tailored to fit their specific needs, thereby strengthening their loyalty to the site. Online clubs are an effective way for radio station websites to tailor their online services. Registration allows the visitors to tell more specifically about their interests and that, in turn, allows the station to be more specific about what info and prizes it sends back to the club member. These are structural solutions to a visitor's needs. They add hard-to-duplicate value to the website and help establish Dupont's third level of relationship marketing.

Communication is another important aspect of online relationship marketing. As with any other relationship marketing situation, communication is important in fostering loyalty for a website, and trust is a large component of loyalty (Thomases 2000). Personal e-mail updates are a 
particularly good way to maintain communication and to foster trust in website visitors (Perez 2000). Two-way communication makes a customer feel like part of a relationship, but unreciprocated communication can undermine trust. For that reason it is important for websites to communicate with their visitors and to do it frequently (Donath 1998). Also, in order to personalize communication with their customers, online companies should use a polite but relaxed style of writing in their e-mail messages (Greenbaum 2000). Communication helps establish Dupont's second level of marketing: socialization. E-mail capabilities along with chat rooms, bulletin boards, D.J. appearances in the community, the option of voting on songs and online clubs are all features that allow listeners to interact with the station and each other. They help form a relational bond with the site and service (Gapper 1998).

Now that it has examined the importance of relationship marketing, how it can apply to online situations, its component attitudes and methods for instilling those attitudes, this study will focus on new research. It will examine the websites of a number of large-market radio stations. It will then identify the elements of relationship marketing that they use and compare them to those identified in the Edison/Arbitron study. That comparison should show whether or not radio station-related websites are using effective 
relationship marketing tactics by providing site visitors with the features that they say they want to see. 


\section{Methodology}

A website's relationship with its visitors differs from the typical

relationship marketing scenario. The webpage is not a tangible product and, while it could be considered a service, no money changes hands. However, websites are valuable business tools and are useful in building relationships between the websites' operators and their customers. If websites meet certain needs of visitors, then those sites will encourage visitors to return regularly, thereby fostering a sense of loyalty and strengthening the relationship between site provider and site visitor. In that sense, a website's basic objective is to encourage repeat visits. But are website designers installing the specific online features that visitors want to see? Will existing site features draw visitors back to the webpage? There is little research on this subject, so this study will examine the relationship-building features used by radio station websites. It will determine whether website designers are actually including the online features that site visitors claim are most important to them. If sites do not include the most popular online features, they are not really satisfying the needs of their visitors and are not encouraging return visits. Those site designers are missing opportunities to build relationships with their customers. 
This study is a content analysis of websites of prominent radio stations in the country. Using online features identified in a previous study, it will note how many websites have each feature. Then it will compare results with that previous study. The previous survey asked website visitors to tell which online features they most wanted to see; it then had them rank those features in order of importance. By comparing results with the previous study; this study will show if highly-ranked (more popular) features actually appear on more websites than do lower-ranked features. If online features do not appear on websites in numbers proportionate to their popularity, that may mean that site designers are failing in meeting their basic objective of meeting visitors needs in order to get them to make return visits. If that's the case, then they are missing opportunities to build relationships with their site visitors. If radio station websites are poorly constructed in terms of meeting customers' needs, then this study can identify the areas in which the websites' designs are lacking and can recommend ways to correct those deficiencies

The sample stations used in this study are from the 50 largest population centers in the United States, according to the 1990 census.

From each market, the study will examine three types of stations: 1.) a classic rock/alternative rock station, 2.) a hip hop/R \& B station, and 3.) a 
top 40/ adult contemporary station. The purpose here is to compare the differences between them in their website construction. These particular formats are in the study because they are similar to one another: They are all music-based (the core interest of their site visitors will be the music). The three formats also focus primarily on music that is new even though the styles of music are different. For that reason classical music stations (the music will not consistently be new); news/talk stations are not, either (they are not music-based).

Each specific station chosen is in the Gail Company Directory of Publications and Broadcast Media. This study will examine one station from each category from each market. If there were more than one station of each category in a market, the station with the greatest broadcast range (measured in wattage) became the subject of the study. If there were two or more stations with the same range in the same category in one market, age of the station was the determining factor. This study does not include public, student or community radio stations. They have different financial constraints than commercial stations do, and those factors could influence the website features they would use.

Each market receives a unique number code (1-50). The letter "A" designates classic rock/alternative rock stations, "B" designates $\mathrm{R} \& \mathrm{~B} / \mathrm{urban}$ 
stations, and "C" designates top 40/a.c. stations. For example, the code for the R\& B station in the Los Angeles market is 2.B.

This study will require coding for the presence or absence of specific features on each website. These features come from a 2000 Edison Media Research/Arbitron survey; it determined which features radio station website visitors most wanted on the webpages they visited. The sample population in the Edison/Arbitron study comes from two sources. The first is a national random sample of Arbitron diary-keepers, contacted and surveyed by telephone (3005 in all). That sample should be generalizable for the purposes of this study because Arbitron diaries are well-respected and widely used by radio stations as a source of information about listening habits. The rest of the Edison/Arbitron survey sample consisted of 14,703 radio station website users, queried using pop-up questionnaires. That, too, should be generalizable, because the sample involves the type of person in whose opinion this study is interested (a relatively Internet-savvy, radio station website visitor). The goal is to determine what site designers are offering visitors to entice them to return. If a station does not have a website, then the study will note that. If a station has a site, but the site will not open, the study will also note that. Finally, if there is no station of a particular format in any of the markets, this study will also note that. The 
presence or absence (denoted by a " 1 " or a " 0 ", respectively) of the

following relationship marketing elements (listed with their code letters) will be the focus of this study:

a. Programming Schedule (which shows air when): list of regular song rotation, specialty shows and air times

b. Location of or Directions to Station Events: schedule of station's appearances in the community and instructions about how to attend

c. Concert Listings: listings or links to listings of live performances coming to the area

d. Top Songs/Artist Playlist: featured musical artists being played on the station or current top songs

e. D. J. Pictures and Information: biographical information about station employees

f. Local Weather: temperature and forecasts for station's listening area

g. E-mail/Contact with Station: ability to e-mail disc jockeys, station managers, and station employees (response time will be measured in days)

h. Coupons: ability to print out coupons that are redeemable at area stores and merchants 
i. Ability to Order Merchandise: order links for station tapes, c.d.'s, clothing, etc. (must be station-related merchandise)

j. List of Local Activities: activities in the community that are not stationsponsored or related (those are covered under "promotional events"); this item does not apply to concerts

k. Online Contest Registration: ability to win prizes through online participation (not simply descriptions of on-air contests)

1. Vote for or Against Songs: option of telling which songs visitor prefers

m. Auxiliary Audio/Video: Internet-only audio or video that has not necessarily been broadcast over the air: mp3's of songs, music videos, et cetera

n. Online Streaming (ability to listen online): ability to listen to the station online (There is one issue to be addressed for online streaming, or broadcasting, over the Internet. Since this study was started, agencies representing commercial voice talent have started looking into whether they can charge twice for any commercial that is simultaneously broadcast on-air and on-line. If something is broadcast online, it is essentially broadcast nationwide and the talent agencies wish to charge stations again for any commercial that is streamed. Naturally, many radio stations, hoping to avoid the extra expense, have shut down their 
streaming capabilities for the moment until the two sides can agree on this matter. For this reason, many stations in the study may not be streaming. This study will, however, specify whether a website offered streaming and then suspended it, or if it never offered streaming at all.)

The previously mentioned letters will identify each marketing element. A "0" or "1", respectively, will indicate the absence or presence of each element.

Once each website is coded for online features, there will be a comparison of these results with those of the Edison/Arbitron internet study to determine whether the features being offered on the most radio station websites are the same ones survey respondents most wish to see. Finally, this study will compare results between formats to see which differences, if any, there are between them. If website designers are not giving site visitors what they say they want, then the designers are not effectively achieving their goals of repeat site visits and stronger relationships between visitors and radio stations. This study should indicate what changes, if any, radio stations should make to strengthen their relationships with their website visitors. 


\section{Results}

On the next page is the table of results of this study. The first column lists each website feature in the order of its popularity ranking according to the Edison/Arbitron study. The next column lists the frequency-ofoccurrence ranking of that feature on the websites surveyed in this study (a ranking of "first" indicates that that feature appeared on more websites than any other, "second" indicates that it appeared second-most frequently, et cetera). The second column also contains a number indicating what percentage of websites surveyed contained that particular feature. The last three columns break down frequency-of-occurrence results according to station format. 
$\underline{\text { Table } 1}$

$\underline{\text { Results }}$

\begin{tabular}{|c|c|c|c|c|}
\hline \begin{tabular}{|l|} 
Edison/Arbitro \\
nPopularity \\
Ranking \\
\end{tabular} & All Websites & \begin{tabular}{|l} 
Rock \\
Station \\
Websites \\
\end{tabular} & $\begin{array}{l}\text { Hip } \\
\text { Hop/R\&B } \\
\text { Websites } \\
\end{array}$ & $\begin{array}{l}\text { Top } \\
\text { 40/A.C. } \\
\text { Websites } \\
\end{array}$ \\
\hline 1. Streaming & 10th (41\%) & $9^{\text {th }}(56 \%)$ & 8th (34\%) & $\begin{array}{l}10 \text { th } \\
(34 \%)\end{array}$ \\
\hline 2. Concert Info & 4th $(64 \%)$ & $1^{\text {st }}(92 \%)$ & 5 th $(42 \%)$ & 4th $(60 \%)$ \\
\hline 3. Playlist & 5 th $(58 \%)$ & $7^{\text {th }}(58 \%)$ & 2nd (62\%) & 7th $(54 \%)$ \\
\hline 4. Contests & 7th (50\%) & $5^{\text {th }}(64 \%)$ & 8th (34\%) & 7th $(54 \%)$ \\
\hline $\begin{array}{l}\text { 5. Loc } \\
\text { Activit }\end{array}$ & 9th & 11th $(36 \%)$ & 10th $(32 \%)$ & $58 \%)$ \\
\hline $\begin{array}{l}\text { 6. Vote on } \\
\text { Songs }\end{array}$ & $12 \mathrm{tt}$ & 13th $(12 \%)$ & 12th & $\begin{array}{l}12 \text { th } \\
(14 \%)\end{array}$ \\
\hline $\begin{array}{l}\text { 7. Local } \\
\text { Weather }\end{array}$ & 6th & $6^{\text {th }}(60 \%)$ & 6th & 4th $(60 \%)$ \\
\hline $\begin{array}{l}\text { 8. Programming } \\
\text { Schedule }\end{array}$ & 8th & $44 \%)$ & 7th ( & 9th (46\%) \\
\hline 9. D.J. Info & $1 \mathrm{st}$ & $2^{\text {nd }}(88 \%)$ & 1st $(70 \%)$ & 1st $(84 \%)$ \\
\hline 10. E-Mail & 2nd & $2^{\text {nd }}(88 \%)$ & 2nd (62\%) & 2nd (74\%) \\
\hline $\begin{array}{l}\text { 11. Station } \\
\text { Events }\end{array}$ & $3 r d($ & 4th $(78 \%)$ & 4th (54\%) & 3rd (64\%) \\
\hline $\begin{array}{l}\text { 12. Auxilliary } \\
\text { Audio/Video }\end{array}$ & 11th $(38 \%)$ & 7th (58\%) & 10th $(32 \%)$ & $\begin{array}{l}11 \text { th } \\
(26 \%)\end{array}$ \\
\hline 13. Coupons & 14th & $8 \%)$ & 13th & $\begin{array}{l}13 \text { th } \\
(12 \%)\end{array}$ \\
\hline $\begin{array}{l}\text { 14. Order } \\
\text { Merchandis }\end{array}$ & 1 & $2 \%)$ & $\%)$ & 14th (0) \\
\hline
\end{tabular}


General Comparisons Between

Edison/Arbitron Popularity Rankings

and the Actual Occurrence of Website Features

This results analysis section will identify overall similarities and discrepancies between website feature popularity (according to the Edison/Arbirtron survey) and the actual frequency of occurrence of those features in this study.

\section{Comparisons for Website Features of All Stations Surveyed}

There was not much similarity between the ranking of the popularity of any particular website feature (determined by the Edison/Arbitron survey) and the rankings of the actual occurrence of that website feature (determined by this survey). That is surprising, assuming that the goal of each website is to generate repeat traffic and, ultimately, to form strong relationships with listeners/site visitors. With that goal in mind, it would stand to reason that the five most popular features, in particular, would appear on more websites than the less popular features, but that is not the case. Only two of the five most popular features in the Edison/Arbitron survey were among the five most frequently occurring features in this survey; the other three were 
between ninth and eleventh in frequency of occurrence. The feature that ranks as the most popular in the Edison/Arbitron survey (online streaming) is tenth in actual frequency of occurrence in this survey. The most frequently-occurring feature in this survey (D.J. Information) ranks only ninth in terms of popularity in the Edison/Arbitron survey.

Only one online feature has the same ranking in popularity in the Edison/Arbitron study as it does in frequency of occurrence in this survey (the programming schedule, ranked eighth in both studies).

Finally, the least popular features were the ones whose popularity rankings most consistently matched their occurrence rankings. Website features that ranked $12^{\text {th }}, 13^{\text {th }}$, and $14^{\text {th }}$ in popularity in the Edison/Arbitron study were all within one rank of that rating in their frequency of occurrence in this survey.

There were fourteen stations overall that did not have a website. This study also found four stations that had websites that would not open. Finally, this study found four instances where a market did not have any stations in one of the three chosen formats. In all, this study examined 129 properly operating radio station websites. 


\section{Comparisons for Website Features}

\section{of Stations in a Particular Format}

This section will make the same popularity-ranking-versus frequency-ofoccurrence-ranking comparison as before but it will break the comparisons down according to the format of the website's radio station. The results are similar to those in the general comparison section:

Rock Station Websites

Only two of the top five most popular features in the Edison/Arbitron survey were also among the five most frequently- occurring features on rock station websites in this survey (Concert Info and Contest Registration); the others were between ninth and eleventh in frequency of occurrence. The most frequently-occurring feature on Rock station websites in this study (Concert Info) is the second-most popular in the Edison/Arbitron survey (this is probably the most drastic difference between formats: in the other two formats and in the website survey overall, the most frequently-occurring feature, D.J. Info, ranked ninth in popularity in Edison/Arbitron). The most 
popular website feature in the Edison/Arbitron study (Online Streaming) only ranks ninth in actual occurrence in this study.

The two least popular features in the Edison/Arbitron survey (Coupons and Order Merchandise) ranked $12^{\text {th }}$ and $14^{\text {th }}$ in frequency of occurrence on rock station websites; those rankings are relatively close to their respective popularity rankings. There were four features (Concert Info, Contests, Local Weather, Coupons) altogether on rock station websites that had frequencyof-occurrence rankings that were only one spot removed from their popularity rankings. Those rankings, too, are slightly more similar to one another than overall ranking comparisons.

More rock stations tended to have websites than did stations in any other surveyed format. Only one rock station in this study had no website at all and only one had a website that would not open. Out of 50 markets in all, this survey analyzed 48 properly functioning Rock station websites.

\section{R\&B Station Websites}

Most features on R\&B websites occur with frequency similar to that of features on the rock station websites. Again, only two of the five most popular features in the Edison/Arbitron survey (Concert Info and Playlist) 
were among the top five most frequently-occurring features in this study; the others rank only ninth through eleventh in frequency of occurrence. The most popular feature in the Edison/Arbitron survey (Streaming) is eighth in actual occurrence, while the most frequently-occurring feature in this study ranks ninth in popularity.

Three features on hip-hop/R\&B websites (Playlist, Local Weather, and Programming Schedule) had frequency of occurrence rankings in this study that were one spot different than their popularity rankings in the Edison/Arbitron survey. The two features ranked $13^{\text {th }}$ and $14^{\text {th }}$ in popularity in Edison/Arbitron (Coupons and Order Merchandise) ranked $13^{\text {th }}$ and $14^{\text {th }}$ in actual occurrence on R\&B websites in this study; these are some of only a few instances where a feature's rankings are exactly the same in this study as in the Edison/Arbitron study.

There were fewer websites in the R\&B/Hip Hop format than in either of the other two formats in this study. Nine of the Hip Hop stations surveyed did not have a website at all, one had a website that would not open, and in two of the markets examined, there were no Hip Hop stations at all. Out of 50 markets in all, there were 38 functioning websites from R\&B/Hip Hop stations surveyed in this study. 
Top 40/Adult Contemporary Station Websites

Features on Top 40 websites occur with similar frequency to features on websites of other formats, with some slight differences. Only one of the five most popular features in the Edison/Arbitron study (Concert Info) ranks in the top five most frequently-occurring features on Top 40 sites (as compared to two of the five most popular features ranking in the top five in terms of occurrence in the other two formats). The most popular feature in the Edison/Arbitron survey (Streaming) is tenth in actual frequency of occurrence on Top 40 websites in this study (compared to ninth in occurrence for Rock and eighth for R\&B). The most frequently-occurring feature on Top 40 sites (D.J. Info) is ranked only ninth in popularity in the Edison/Arbitron survey.

Three features (Local Activities, Programming Schedule, Auxilliary Audio/Video) have one ranking difference between their popularity as determined by the Edison/Arbitron survey and their frequency of occurrence as determined by this study. Also, as in the other formats, the least popular features occur the least frequently; the features that rank $13^{\text {th }}$ and $14^{\text {th }}$ in popularity in the Arbitron survey (Coupons and Order Merchandise) rank $13^{\text {th }}$ in $14^{\text {th }}$ in frequency of occurrence in this study. 
Top 40/Adult Contemporary stations with websites were more numerous than Hip Hop stations with websites, but less numerous than Rock stations with webpages. Four of the AC stations in this study did not have websites, two had websites that would not open, and in one case, there was a market that had no Top 40/AC station at all. Out of 50 markets, this study examined 43 properly functioning Top 40/AC radio station websites in all.

Overall, it appears that classic/alternative rock stations are the most web savvy. Their websites contain more features in general than do websites in either of the other two formats. For example, the most common feature on classic rock websites (Concert Info) occurs on 92 percent of the webpages surveyed, but the most common feature on hip hop websites (D.J. Info) only appears on 70 percent of the sites. The most common feature on top 40 sites (again, D.J. Info) is on 84 percent of the surveyed sites. In nearly every case, online features on the classic rock websites consistently occur with more frequency than do their counterparts on websites of the other two formats. Even taking into account the greater number of classic rock websites in this study, each feature still appeared on a higher percentage of rock station webpages than they did on sites of either other format. Rock stations were also more likely to have websites than were their Hip Hop or Top 40 counterparts. Forty-eight Rock stations (out of the 50 markets 
examined) in this study had functioning websites, compared to $43 \mathrm{AC} / \mathrm{Top}$ 40 stations with functioning websites and only 38 R\&B/Hip Hop stations with wepbages that work properly.

\section{Comparisons of the Occurrence of Each Website Feature With Its Edison/Arbitron Rankings}

This results analysis section will compare the occurrence frequency of each website feature with its popularity ranking given in the Edison/Arbitron study. This takes another look at the question of whether or not the features that are most popular with website visitors are actually on more websites than are less popular features. This section will deal with each website feature individually; it will involve a comparison of differences between a feature's popularity rank (as determined by the Edison/Arbitron study) and its actual occurrence rank (as determined by this study).

Streaming

The ability to listen to the station online, the $10^{\text {th }}$-most widespread feature, occurred on 41 percent of the surveyed websites. In the Edison/Arbitron survey, however, it was the most popular feature listed by respondents, 
which is a nine-spot difference. If designers are attempting to include on their websites features that site visitors want to see, this should be the most frequently included feature. Because of rights issues, a number of stations once offered online streaming but have temporarily disconnected it. Those stations are included in the total number of websites offering streaming. If they are removed from the surveyed total, the number of websites that offer streaming drops by almost half. According to those numbers and comparisons, online streaming is a considerably under-used feature, especially if site designers want to build strong relationships by offering visitors features they claim to most want to see.

\section{Concert Listings}

A list of upcoming concerts in the station's broadcasting area is the fourth most prevalent website feature in this study; it appears on 64 percent of the examined web pages. This feature is much more appropriately represented in comparison to its Edison/Arbitron ranking; respondents ranked it second in terms of popularity and importance. That is a difference of only two ranking spots. It is also ranked in the top five in terms of popularity and 
frequency of occurrence. In this instance, website construction more appropriately reflects what web page visitors claim they want to see.

\section{Top Songs}

A list of top songs currently being played on the radio station is the fifth most widespread website feature; it appears on 58 percent of the surveyed websites. Lists of top songs rank third in popularity in the Edison/Arbitron ranking, which is a difference of only two spots. Again, this feature's ranking is a more accurate reflection of what website visitors say they want to see on a radio station's website; it, along with concert information, ranks in the top five in both popularity and actual occurrence.

\section{Contest Registration}

The ability to register for contests online ranks seventh in terms of frequency of appearance; it is included on exactly 50 percent of the surveyed radio station websites. The Edison/Arbitron survey ranks it fourth in terms of popularity. With a ranking difference of three spots, contest registration 
appears on websites somewhat less often than its popularity indicates it should.

Local Activities

\begin{abstract}
A list of non-station-related activities in the station's broadcast range ranks ninth in terms of frequency of occurrence; it showed up on 42 percent of the websites surveyed. However, respondents on the Edison/Arbitron survey thought the local activities list was much more important; they ranked it fifth in terms of importance, making for a discrepancy of four ranking spots.
\end{abstract}

\title{
Vote On Songs
}

The online feature that allows site visitors to vote on their favorite songs is included on 13 percent of the radio station websites surveyed, ranking $12^{\text {th }}$ in occurrence; that's considerably less often than its popularity ranking of $6^{\text {th }}$ (according to Edison/Arbitron) suggests it should appear. This is another example of a situation in which site visitors express a moderate amount of interest in a feature that is too rarely included on websites. 
Local Weather

Information on local weather appears on 54 percent of the surveyed web pages, making it the sixth most frequently appearing feature. The

Edison/Arbitron survey ranks local weather information as the seventh most popular online feature for radio stations. Its frequency of occurrence is an accurate reflection of its expressed popularity; there is only a difference of one ranking spot between its Edison/Arbitron ranking and its frequency of appearance in the new research.

Programming Schedule

A list of what will be broadcast on a station each day is included on 43 percent of surveyed websites, making programming schedules the eighthmost frequently occurring online feature. The Edison/Arbitron study also ranks programming schedules eighth in popularity, making this feature the only exact match between the two studies. 


\section{DJ Information}

Biographical information about a station's disc jockeys is the most widely included feature on all surveyed radio station websites. It is included on 80 percent of the websites surveyed; that makes it the most frequentlyoccurring feature. However, it is ranked only ninth in the Edison/Arbitron study. DJ information is a disproportionately widespread feature considering its relatively low popularity; there is a difference of eight rankings between its popularity and its actual frequency of occurrence. Website designers should probably have included other, more popular, features in greater numbers than DJ information in order to provide visitors with features they claim to want to see.

\section{E-Mail Contact}

The ability to contact radio stations via e-mail is the second most widespread feature on radio station websites; 74 percent of the web pages surveyed featured e-mail links to the radio station. However, the e-mail feature only ranked tenth in the Edison/Arbitron study. Like D.J. information, this feature appears on websites far more than its popularity 
indicates that it should; there is an eight-ranking difference between popularity of this feature and its actual frequency of occurrence.

\section{Station Events}

The third most prevalent website feature found in this study is a listing of upcoming station events in the community. Station event lists appeared on 65 percent of the web pages surveyed. As with the top two features, however, when compared with its popularity ranking, the occurrence of the station event feature is disproportionately high. It only ranks eleventh in the Edison/Arbitron survey; that is a difference of eight ranking spots.

\section{Auxiliary Audio/Video}

Audio and video archives (as internet streaming) that visitors can access from a radio station website rank eleventh in terms of occurrence; they are on 38 percent of the surveyed websites. The Edison/Arbitron study had auxiliary audio/video archives listed twelfth in terms of importance, according to respondents. This website feature occurs about as often as its popularity suggests it should; there is only one ranking spot difference 
between the two surveys and they both give the auxiliary audio/video feature a low ranking.

\section{Coupons}

The ability to print out coupons from radio station websites, along with merchandise ordering, is rarely found on the surveyed webpages; only 10 percent include this feature, which makes it the least frequently occurring feature in this study. Those findings are in accordance with the results of the Edison/Arbitron survey. Respondents in that study showed little interest in the ability to print out coupons from websites; they ranked the feature $13^{\text {th }}$ out of 14 in terms of importance (only merchandise ordering was less popular among Edison/Arbitron respondents).

Order Merchandise

The ability to order radio station merchandise occurs rarely on the surveyed websites (12 percent), ranking $13^{\text {th }}$ in occurrence in the new study. That is appropriate, however, since site visitors express little interest in the abilty to order merchandise. According to the Edison/Arbitron survey this feature 
ranks $14^{\text {th }}$ (last) in popularity, so website designers have included this feature accordingly.

\section{Comparison of Website Feature}

\section{Occurrence Between Formats}

This analysis section will compare the occurrence of each website feature across station formats. It will compare the way each feature ranks on classic rock websites with the way it ranks on hip-hop websites and on top 40 websites. The purpose of this section is to determine how each format differs from the others in terms of the frequency of website features.

Streaming

The streaming feature, which allows visitors to listen to the radio station online, is ranked highest on hip hop websites. It is tied for $8^{\text {th }}$ and occurs on 34 percent of the surveyed sites. This feature ranks $9^{\text {th }}$ in the classic rock format; however, it occurs on 56 percent of the surveyed classic rock sites. Even though it is somewhat more popular on the hip hop sites when 
compared to other features, it appears on a greater percentage of the classic rock sites. It ranks $10^{\text {th }}$ on top 40 websites ( 34 percent).

\section{Concert Listings}

Concert listings occur most often on classic rock sites where they are the single most widespread feature (92 percent of websites have it). Top 40 webpages have concert listings tied for $4^{\text {th }}$ (60 percent) with the Local Weather feature, and hip-hop stations rank them the lowest at $5^{\text {th }}(42$ percent). As with station events, there is a wide range of occurrence between the formats for concert listings.

Playlist

Playlists are most common on hip-hop websites; they are ranked $2^{\text {nd }}$ out of all features (occurring on 62 percent of the surveyed web pages). Classic rock websites ( 58 percent) and top 40 websites ( 54 percent) both rank playlists $7^{\text {th }}$ (tied in each case with other features). In this case, too, there is some discrepancy between formats in terms of rankings, but the percentages are somewhat close together. 
Online Contest Registration

Online contest registration is most common on classic rock websites; they rank $5^{\text {th }}$ of all features, appearing on 64 percent of the websites. This feature is tied for $7^{\text {th }}$ (54 percent) on top 40 sites. It is least common on hip hop sites, where it is tied for $8^{\text {th }}$ and appears on 34 percent of the surveyed webpages.

Local Activities

A listing of local activities appears most frequently on top 40 websites with a ranking of $6^{\text {th }}$ (58 percent). This feature ranks tied for $10^{\text {th }}$ on hip hop sites (32 percent) and it ranks $11^{\text {th }}$ on classic rock sites ( 36 percent). The Local Activities feature appears considerably more often on top 40 websites than on the websites of the other two formats.

Vote on Songs

The ability to vote on favorite songs is consistently rare, in terms of both ranking and occurrence, on websites of all three formats. It ranks $12^{\text {th }}$ on 
both hip hop websites (14 percent) and top 40 websites (14 percent). It ranks a little lower on classic rock web pages at $13^{\text {th }}$ (12 percent).

Local Weather

The local weather website feature has fairly consistent rankings across all three formats. Its ranks $4^{\text {th }}$ on the top 40 station sites (tied with Concert Info: 60 percent), $5^{\text {th }}$ on hip-hop webpages (also tied with concert listings: 42 percent), and $6^{\text {th }}$ on the classic rock sites ( 60 percent).

Programming Schedule

The programming schedule feature ranks highest on hip-hop stations at $7^{\text {th }}$ (appearing on 40 percent of the surveyed websites), next highest on top 40 stations at $9^{\text {th }}$ (46 percent) and lowest on classic rock stations at $10^{\text {th }}(44$ percent). 


\section{D.J. Info}

D.J. information is the most common feature on both hip-hop websites (70 percent) and top 40 websites ( 84 percent); it ranks $1^{\text {st }}$ on both. It is tied for second (with E-Mail) on classic rock stations ( 88 percent). This feature ranks consistently high across all formats.

\section{E-Mail Contact}

The ability to contact radio stations via e-mail occurs consistently on the websites of all formats. It ranks $2^{\text {nd }}$ among all features on all three formats. On classic rock station websites, it is tied with D.J Info (88 percent) for $2^{\text {nd }}$. On hip hop stations, its tied for $2^{\text {nd }}$ (62 percent) with the Playlist feature. On top 40 websites, the feature is also ranked $2^{\text {nd }}$ with appearances on 74 percent of the surveyed sites. 


\section{Station Events}

The station events feature is most common on Top 40/A.C. stations, where it ranks 3rd among all features (it occurs on 64 percent of surveyed sites). It ranks $4^{\text {th }}$ on classic rock stations (78 percent) and on hip-hop stations (54 percent). In terms of rankings, this feature is fairly consistent across all three station formats. However, there is a considerable difference between formats when looking at percentage of occurrence.

\section{Auxiliary Audio/Video}

Audio and video archives appears most frequently on classic rock websites; they are tied at $7^{\text {th }}$ with an occurrence percentage of 58 percent. This feature is tied for $10^{\text {th }}$ on hip hop sites ( 32 percent) and ranks $11^{\text {th }}$ on top 40 sites (26 percent). 


\section{Coupons}

The ability to print coupons off of radio station websites is consistently scarce on all three format websites. It ranks $13^{\text {th }}$, next to last, on both hip hop websites (10 percent) and top 40 websites (12 percent). It ranks $14^{\text {th }}$, dead last, on websites for classic rock stations ( 8 percent). The frequency of this feature is fairly consistent, in terms of ranking and percentage, across all three formats.

Ordering Merchandise

The ability to order merchandise online ranks $12^{\text {th }}$ on classic rock station websites; it appears on 32 percent of surveyed webpages. It ranks $14^{\text {th }}$ (last) on both hip hop sites ( 4 percent) and top 40 sites (no occurrences at all). The merchandise ordering feature ranks consistently low across all three formats, though there is some variation in its percentage of occurrence. 


\section{Discussion}

\section{and}

\section{Future Research}

The relatively low frequency of occurrence of the most popular online features in this study is significant. If website designers want to build strong relationships with listeners/site visitors, then the most popular features would be obvious choices to install on a radio station's website. If site designers know that these are the most popular features, it stands to reason that they would make it a priority to include those features on their website. That is not the case. In this study, less popular features generally appear on more websites than do more popular ones. Considering their goal of stronger relationships through increased site traffic, this is not an effective tactic. That leads to one of several assumptions. Site designers are not aware of listener preferences, they are aware of preferences and do not consider them important, or they choose features for their websites based on criteria other than popularity (price or ease of installation, for example). In any case, the radio stations with these sites are not effectively using website construction to build relationships with their listeners. Listeners will visit sites where they receive some sort of value. They have already 
said that certain online features are important to them. If stations do not provide those features or do not provide very many of them, they are not giving listeners the value they are seeking. Listeners will not visit those sites very often or will not visit them at all and these radio stations will have missed an opportunity to build stronger relationships with those listeners. The stations in this survey, when choosing website features, do not seem to have priorities in accordance with the Edison/Arbitron results. Site designers are not selecting website designs based on what webpage visitors say they want to see.

One possibility for this might be that site designers choose online features by convenience rather than according to relationship marketing strategy. For example, Online Streaming is the most popular feature but occurs on relatively few websites. Setting up audio streaming on a website is a somewhat technically involved process; site designers might have decided not to bother and to simply install less involved features. Similarly, the Local Activities feature is popular, but not widely occurring. While not technically difficult to install, it would require some research into events in the community and it would require regular updates. Conversely, D.J. Info and E-Mail are not especially popular, but they rank first or second in occurrence overall and in every radio station format. That could be because 
they are both easy to put on a website; E-mail capability is very common and D.J. Info simply requires the posting of answers to a questionnaire. That might be one explanation for discrepancies between a feature's popularity ranking and its frequency-of-occurrence ranking.

Another possible reason for the difference between the popularity of online features (according to the Edison/Arbitron survey) and the actual occurrence of those features (as determined by this study) is market peculiarity. Listeners in a particular region might have different priorities regarding online features than did the Edison/Arbitron respondents as a whole. Certain stations may have performed their own listener surveys and found that their website visitors had different priorities when it came to online features. Either of these possibilities could explain the discrepancies found in this study; they are also promising topics for subsequent studies. Future research about radio station websites' relationship marketing should probably focus on why site designers choose to install particular online features while not installing others. This sort of study would probably need to take the form of interviews or questionnaires. That would help to explain the popularity/occurrence discrepancies. Other research could focus on repeat visitors to radio station websites and their reasons for 
returning. It could also be useful to examine differences in radio station websites across markets and geographical regions.

Relationship marketing is an effective, important strategy for any business, radio stations included. A station's website can be a useful tool for fostering relationships with its listeners if someone designs the site properly. It would be valuable to now determine why so many radio stations seem to disregard the preferences of their site visitors. 


\section{Appendixes}

Markets and Stations Analyzed

1. New York City, NY

A. classic/alternative rock: WXRK-FM 92.3

B. $r \& b / h i p$ hop: WRKS-FM 98.7

C. top 40/adult contemporary: WPLJ-FM 95.5

2. Los Angeles, CA

A. classic rock/alternative rock: KROQ-FM 106.7

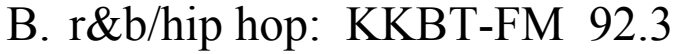

C. top 40/adult contemporary: KBIG-FM 104.3

3. Chicago, IL

A. classic rock/alternative rock: WXCD-FM 94.7

B. $r \& b / h i p ~ h o p:$ WGCI-FM 107.5

C. top 40/adult contemporary: WLIT-FM 93.9

4. Houston, TX

A. classic rock/alternative rock: WKRW-FM 93.7

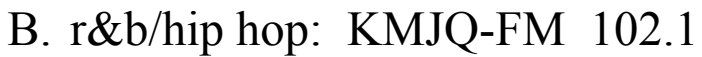

C. top 40/adult contemporary: KODA-FM 99.1

5. Philadelphia, PA

A. classic rock/alternative rock: WMMR-FM 93.3

B. r\&b/hip hop: WUSL-FM 98.9

C. top 40/a.c: WSNI-FM 104.5

6. San Diego, CA

A. classic rock/alternative rock: KGB-FM 101.5

B. $\mathrm{r} \&$ b/hip hop: XHTZ-FM 90.3

C. top 40/a.c: KJQY-FM 94.1 


\section{Detroit, MI}

A. classic rock/alternative rock: WCSX-FM 94.7

B. $r \& b / h i p$ hop: WJLB-FM 97.9

C. top 40/a.c: WMXD-FM 92.3

8. Dallas, TX

A. classic rock/alternative rock: KZPS-FM 92.5

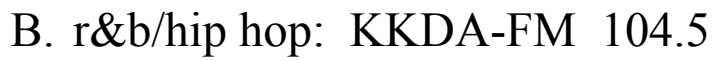

C. top 40/a.c.:KHLS-FM 106.1

9. Phoenix, AZ

A. classic rock/alternative rock: KZON-FM 101.5

B. r\&b/hip hop: KISO-AM 1230

C. top 40/a.c.: KESZ-FM 99.9

10. San Antonio, TX

A. classic rock/alternative rock: KZEP-FM 104.5

B. $r \& b /$ hip hop: KSJL-AM 760

C. top 40/a.c.: KQXT-FM 101.9

11. San Jose, CA

A. classic rock/alternative rock: KFOX-FM 98.5

B. $r \& b / h i p ~ h o p:$ none found in market

C. top 40/a.c.: KARA-FM 105.7

12. Baltimore, MD

A. classic rock/alternative rock: WOCT-FM 104.3

B. r\&b/hip hop: WXYV-FM 102.7

C. top 40/a.c.: WLIF-FM 101.9

13. Indianapolis, IN

A. classic rock/alternative rock: WFBQ-FM 95.1

B. $r \& b / h i p ~ h o p:$ WTLC-FM 105.7

C. top 40/a.c.: WXXP-FM 97.9 
14. San Fransisco, CA

A. classic rock/alternative rock: KFOG-FM 104.5

B. $r \& b / h i p ~ h o p:$ KMEL-FM 106.1

C. top 40/a.c.: KIOI-FM 101.3

15. Jacksonville, FL

A. classic rock/alternative rock: WFYV-FM 104.5

B. $\mathrm{r} \& b /$ hip hop: WJBT-FM 92.7

C. top 40/a.c.: WEJZ-FM 96.1

16. Columbus, $\mathrm{OH}$

A. classic rock/alternative rock: WBZX-FM 99.7

B. r\&b/hip hop: WCKX-FM 106.3

C. top 40/a.c.: WNCI-FM 97.9

17. Milwaukee, WI

A. classic rock/alternative rock: WLZR-FM 102.9

B. r\&b/hip hop: WNOV-AM 860

C. top 40/a.c.: WLTQ-FM 97.3

18. Memphis, TN

A. classic rock/alternative rock: WEGR-FM 102.7

B. r\&b/hip hop: WHRK-FM 97.1

C. top 40/a.c.: WMC-FM 99.7

19. Washington, D.C.

A. classic rock/alternative rock: WHFS-FM 99.1

B. r\&b/hip hop: WKYS-FM 93.9

C. top 40/a.c.: WRQX-FM 107.3

20. Boston, MA

A. classic rock/alternative rock: WZLX-FM 100.7

B. $r \& b / h i p$ hop: WJMN-FM 94.5

C. top 40/a.c.: WBMX-FM 98.5 
21.Seattle, WA

A. classic rock/alternative rock: KZOK-FM 102.5

B. $r \& b / h i p ~ h o p:$ KUBE-FM 93.3

C. top 40/a.c.: KPLZ-FM 101.5

22. El Paso, TX

A. classic rock/alternative rock: KLAQ-FM 95.5

B. $r \& b / h i p ~ h o p:$ KPRR-FM 102.1

C. top 40/a.c.: KSII-FM 93.1

23. Cleveland, $\mathrm{OH}$

A. classsic rock/alternative rock: WMMS-FM 100.7

B. $r \& b / h i p ~ h o p:$ WZAK-FM 93.1

C. top 40/a.c.: WDOK-FM 102.1

24. New Orleans, LA

A. classic rock/alternative rock: WRNO-FM 99.5

B. r\&b/hip hop: WQUE-FM 93.3

C. top 40/a.c.: WEZB-FM 97.1

25. Nashville-Davidson, TN

A. classic rock/alternative rock: WNRQ-FM 105.9

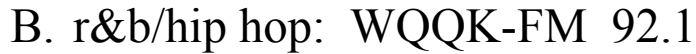

C. top 40/a.c.: WQZQ-FM FM 102.5

26. Denver, CO

A. classic rock/alternative rock: KRFX-FM 103.5

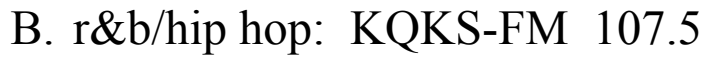

C. top 40/a.c.: KOSI-FM 101.1

27. Austin, TX

A. classic rock/alternative rock: KPEZ-FM 102.3

B. $r \& b / h i p ~ h o p: K B Q T-F M ~ 104.3$

C. top 40/a.c.: KKMJ-FM 95.5 
28. Fort Worth, TX
A. classic rock: KEGL-FM 97.1
B. $r \& b / h i p ~ h o p:$ KBFB-FM 97.9
C. top 40/a.c.: KDMX-FM 102.9

29. Oklahoma City, OK
A. classic rock/alternative rock: KATT-FM 100.5

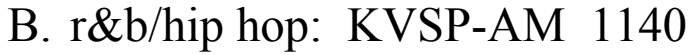
C. top 40/a.c.: KMGL-FM 104.1

30. Portland, OR
A. classic rock/alternative rock: KGON-FM 92.3
B. $r \& b / h i p ~ h o p: K X J M-F M ~ 95.5$
C. top 40/a.c.: KRSK-FM 105.1

31. Kansas City, MO
A. classic rock/alternative rock: KCFX-FM 101.1
B. $r \& b / h i p$ hop: KPRS-FM 103.3
C. top 40/a.c.: KUDL-FM 98.1

32. Long Beach, CA
A. classic rock/alternative rock: KNAC-FM 93.5
B. $r \& b / h i p ~ h o p:$ none listed in market
C. top 40/a.c.: none listed in market

33. Tucson, AZ
A. classic rock/alternative rock: KLPZ-FM 96.1
B. $r \& b / h i p ~ h o p:$ KOHT-FM 98.3
C. top 40/a.c.: KMXZ-FM 94.9

34. St. Louis, MO
A. classic rock/alternative rock: KSHE-FM 94.7
B. r\&b/hip hop: KMJM-FM 107.7
C. top 40/a.c.: WKBQ-FM 104.1

35. Charlotte, NC
A. classic rock/alternative rock: WRFX-FM 99.7
B. $r \& b / h i p ~ h o p:$ WPEG-FM 98.1
C. top 40/a.c.: WLNK-FM 107.9 
36. Atlanta, GA

A. classic rock/alternative rock: WZGC-FM 92.9

B. $r \& b / h i p ~ h o p:$ WBTS-FM 95.5

C. top 40/a.c.: WSB-FM 98.5

37. Virginia Beach, VA

A. classic rock/alternative rock: WNOR-FM 99.1

B. $r \& b / h i p ~ h o p:$ WBHH-FM 92.1

C. top 40/a.c.: WWDE-FM 101.3

38. Albuquerque, NM
A. classic rock: KHTZ-FM 100.3
B. $r \& b / h i p ~ h o p:$ KISS-FM 97.3
C. top 40/a.c.: KKSS-FM 93.7

39. Oakland, CA

A. classic rock/alternative rock: KCNL-FM 104.9

B. $\mathrm{r} \& \mathrm{~b} /$ hip hop: KMEL-FM 105.9

C. top 40/a.c.: no stations listed in market

40. Pittsburgh, PA

A. classic rock/alternative rock: WDVE-FM 102.5

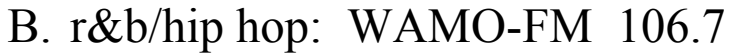

C. top 40/a.c.: WLTJ-FM 92.9

41. Sacramento, CA
A. classic rock/alternative rock: KZZO-FM 100.5
B. r\&b/hip hop: KBMB-FM 103.5
C. top 40/a.c.: KYMX-FM 96.1

42. Minneapolis, MN

A. classic rock/alternative rock: WLOL-FM 100.3

B. r\&b/hip hop: KMOJ-FM 89.9

C. top 40/a.c.: WXPT-FM 104.1 
43. Tulsa, OK

A. classic rock/alternative rock: KMOD-FM 97.5

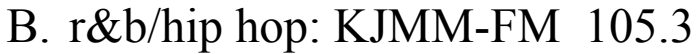

C. top 40/a.c.: KRAV-FM 96.5

44. Honolulu, HI

A. classic rock/alternative rock: KAHA-FM 105.9

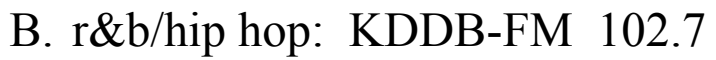

C. top 40/a.c.: KSSK-FM 92.3

45. Cincinnati, $\mathrm{OH}$

A. classic rock/alternative rock: WEBN-FM 102.7

B. $r \& b / h i p ~ h o p:$ WIZF-FM 100.9

C. top 40/a.c.: WRRM-FM 98.5

46. Miami, FL

A. classic rock/alternative rock: WZTA-FM 94.9

B. $r \& b / h i p ~ h o p:$ WEDR-FM 99.1

C. top 40/a.c.: WPOW-FM 96.5

47. Fresno, CA

A. classic rock/alternative rock: KJFX-FM 95.7

B. $r \& b /$ hip hop: KBOS-FM 94.9

C. top 40/a.c.: KAAT-FM 103.1

48. Omaha, NE

A. classic rock/alternative rock: KKCD-FM 92.3

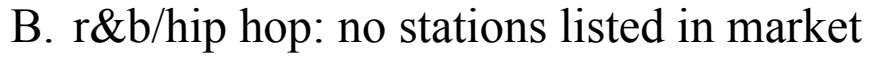

C. top 40/a.c.: KSRZ-FM 104.5

49. Toledo, $\mathrm{OH}$

A. classic rock/alternative rock: WIOT-FM 104.7

B. $r \& b / h i p ~ h o p:$ WIMX-FM 95.7

C. top 40/a.c.: WRVF-FM 101.5 
50. Buffalo, NY

A. classic rock/alternative rock: WGRF-FM 96.9

B. $r \& b / h i p ~ h o p:$ WBLK-FM 93.7

C. top 40/a.c.: WJYE-FM 96.1 
Number of Websites

With Each Feature

Content Analysis Results for All Stations
a. Programming Schedule: 65
b. Station Events: $\quad 98$
c. Concert Info: 97
d. Playlist: 87
e. D.J. Info: 121
f. Local Weather: 81
g. E-Mail: 112
h. Coupons: 15
i. Ordering Merchandise: 18
j. Local Activities: $\quad 63$
k. Contest Registration: $\quad 76$
1. Vote On Songs: 20
m. Auxiliary Audio/Video: 58
n. Streaming: 32
n. (disconnected): $\quad 30$

Content Analysis Results for Classic Rock/Alternative Rock Stations
a. Programming Schedule: 22
b. Station Events: $\quad 39$
c. Concert Info: $\quad 46$
d. Playlist: 29
e. D.J. Info: 44
f. Local Weather: $\quad 30$
g. E-Mail: 44
h. Coupons: 4
i. Order Merchandise: 16
j. Local Activities: $\quad 18$
k. Online Contests: 32
1. Vote On Songs: 6
m. Auxiliary/Audio Video:29
n. Streaming: $\quad 12$
n. (disconnected): 16 
Content Analysis Results for R\&B/Hip Hop Stations
a. Programming Schedule: 20
b. Station Events: 27
c. Concert Info: 21
d. Playlist: 31
e. D.J. Info: 35
f. Local Weather: 21
g. E-Mail: 31
h. Coupons: 5
i. Order Merchandise: 2
j. Local Activities: $\quad 16$
k. Contest Registration: 17
1. Vote On Songs: 7
m. Auxiliary Audio/Video: 16
n. Streaming: 11
n.(disconnected) 6

Content Analysis Results for Top 40/Adult Contemporary Stations
a. Programming Schedule: 23
b. Station Events: $\quad 32$
c. Concert Info: $\quad 30$
d. Playlist: 27
e. D.J. Info: 42
f. Local Weather: 30
g. E-Mail: 37
h. Coupons: 6
i. Order Merchandise: 0
j. Local Activities: 29
k. Contest Registration: 27
1. Vote On Songs: 7
m. Auxiliary Audio/Video: 13
n. Streaming: 9
n. (disconnected): 8 


\section{Works Cited}

“...And Website Dont's.” Business and Management

Practices 9.5 (1998): 5-6.

Berry, Leonard. "Relationship Marketing of Services - Growing Interest, Emerging Perspectives." Journal of the Academy of Marketing Science 23.4 (1995): 236-246.

Bitner, Mary Jo. "Building Service Relationships: It's All About Promises." Journal of the Academy of Marketing Sciences 23.4 (1995): 246-252.

Calonius, Henrik. “A Buying Process Model.” In Innovative Marketing-A European Perspective. Eds. Keith Blois and Stephen Parkinson. England: University of Bradford., 1988. 86-103.

Cotrell, Richard. "Proactive Versus Reactive Customer Contact." Mobius 39 (1994): 25-28.

Crosby, Lawrence, Kenneth Evans and Deborah Cowles. "Relationship Quality in Services Selling: An Interpersonal Influence Perspective." Journal Of Marketing 54 (1990): 68-81.

Czepiel, John. "Services Encounters and Service Relationships: Implications for Research." Journal of Business Research 20 (1990): 13-21.

Donath, Bob. "Slow E-Mail Response Torpedoes Marketing Efforts." Marketing News 31 Aug. 1998: 5-7

Dupont, Randall. "Relationship Marketing: A Strategy for ConsumerOwned

Utilities in a Restructured Industry." Management Quarterly 38.4 (1998): $11-17$.

Gale Directory of Publications and Broadcast Media. Detroit, MI: Gale Research., 1990. 
Ganesan, Shankar. "Determinants of Long-Term Orientation in Buyer-Seller Relationships.” Journal of Marketing 58.2 (1994): 1-20.

Gapper, Justina. “Keep 'em Coming Back for More.” New Media Age 7 May 1998: 10-15.

Garbarino, Ellen, and Mark Johnson. "The Different Roles of Satisfaction, Trust, and Commitment in Customer Relationships." Journal of Marketing 63.2 (1999): 70-102.

Greenbaum, Michael. "Emotional Intelligence Takes Customer Loyalty to a Higher Level.” Boardwatch Magazine 14.7 (2000): 120-122.

Gronroos, Christian. Service Management and Marketing. New York: Lexington, 1990.

Levitt, Theodore. "Marketing Intangible Products and Product Intangibles." Harvard Business Review 59 (1981): 94-102.

Marshall, R.A., B.A. Palmer and S.N. Weisbart. "The Nature and Significance of the Agent-Policy Holder Relationship." CLU Journal 33 (1979): 44-53.

Morgan, Robert, and Shelby Hunt. "The Commitment-Trust Theory of Relationship Marketing.” Journal of Marketing 58.3 (1994): 20-39.

Perez, Jennifer. "Loyalty Programs Fail to Deliver the Goods." Business and

Management Practices 13.6 (2000): 25-26.

Pisharodi, Mohan, and John Langley. "A Perceptual Process Model of Customer Service Based on Cybernetic/Control Theory." Journal of Business Logistics 11.1 (1990): 26-49.

"Radio Station Web Site Content: An In Depth Look." Edison Media Research. Online. Internet. September 2000. 
Reicheld, Frederick and W. Earl Sasser, Jr. "Zero Defections: Quality

Comes

to Services." Harvard Business Review 68 (1990): 105-111.

Schlenker, B.R., B. Helm and J.T. Tedeschi. "The Effects of Personality and Situational Variables on Behavioral Trust." Journal of Personality and Social Psychology 25.3 (1973): 419-427.

Sharma, Arun, et al. "Antecedents and Consequences of Relationship Marketing; Insights from Business Service Salespeople.” Industrial Marketing Management 28.6 (1999): 1-37.

Thomases, Hollis. "Loyalty is the True Measure of Success." iMarketing News 2.7 (2000): 24-28. 